\title{
Multistenting during balloon-assisted ERCP using small diameter plastic stents in patients with surgically altered upper gastrointestinal anatomy
}
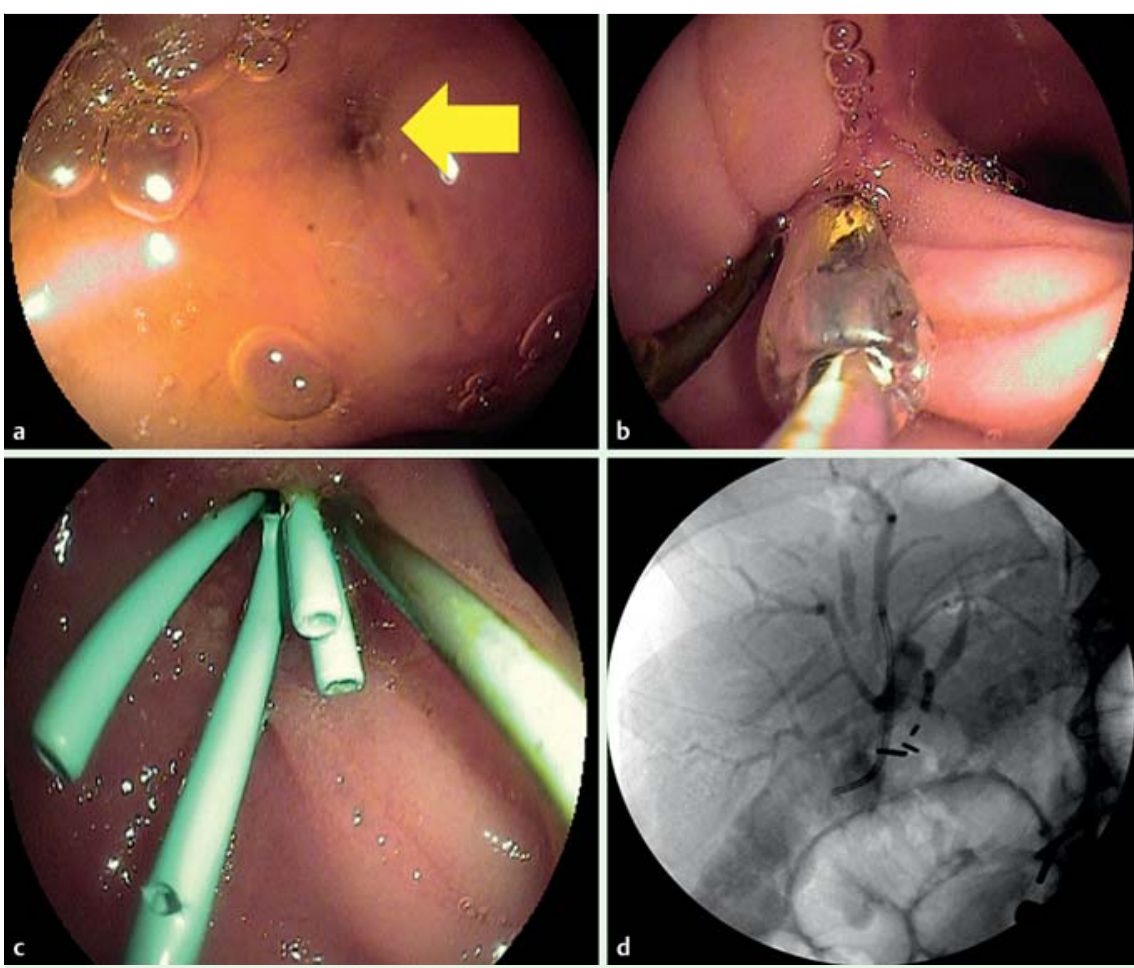

Fig. 1 Use of multistenting in balloon-assisted endoscopic retrograde cholangiopancreatography (ERCP). a The hepaticojejunostomy was highly stenotic (yellow arrow). $\mathbf{b}$ The stricture was dilated with a controlled radial expansion (CRE) balloon. c Endoscopic view of multiple 5-Fr pancreatic plastic stents inserted into the bile duct across the hepaticojejunostomy. $\mathbf{d}$ Fluoroscopic view of the multiple plastic stents.

Balloon-assisted endoscopic retrograde cholangiopancreatography (ERCP) is now commonly used to treat disorders of the pancreatobiliary tract in patients with surgically altered upper gastrointestinal (GI) tract anatomy [1 -3]. However, when either the short or long ERCP scopes have arrived at a tortuous position during the procedure, the ability to deliver accessories such as plastic or metal stents into the biliary tract is limited. Furthermore, the relatively small diameter of the working channel of these scopes limits the possibility of using large stents. In this report, we describe the concept and technique of multistenting using small diameter stents to treat biliary tract strictures.

Five patients (two women, three men; mean age 53 years, range $21-69$ ) had undergone orthotopic liver transplantation with Roux-en-Y hepaticojejunostomy, and had subsequently developed hepaticojejunostomy stenosis (๑ Fig. 1, @ Video 1).
Because of the long and tortuous position of the scope it was impossible to advance standard diameter plastic stents (10-Fr or 7-Fr) ( $\odot$ Fig. 2, $\odot$ Video 1). Therefore, we elected to use several 5-Fr plastic stents. After the stricture had been successfully dilated using a through-the-scope balloon, an extra-long wire $(650 \mathrm{~cm}$, Metro guidewire; Cook, Winston-Salem, USA) was advanced into the biliary tract. Next, five plastic pancreatic stents of small diameter (5-Fr) were inserted individually into the bile duct across the stricture ( $\bullet$ Video 1 ). These stents resulted in a cumulative

\section{Video 1}

Multistenting during balloon-assisted endoscopic retrograde cholangiopancreatography (ERCP) using small (5-Fr) plastic stents in patients with surgically altered upper gastrointestinal (GI) anatomy.

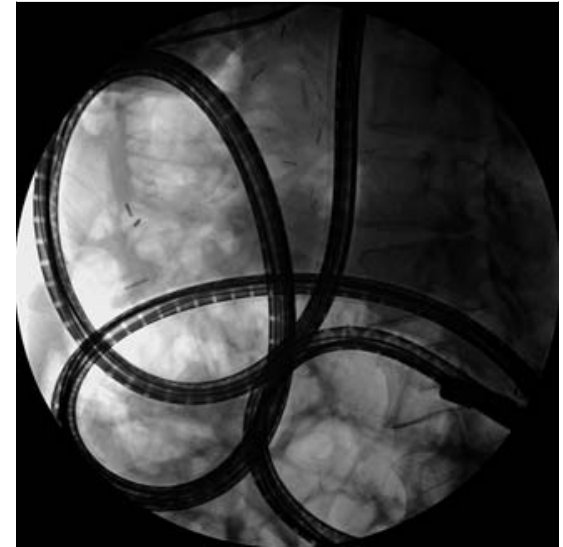

Fig. 2 Because of the long and tortuous position of the scope, it was impossible to advance standard diameter stents through a stenosis in a patient with Roux-en-Y hepaticojejunostomy.

diameter of $25 \mathrm{Fr}$ (or $8 \mathrm{~mm}$ as each stent is $1.6 \mathrm{~mm}$ in diameter), which is the equivalent of two and a half 10-Fr biliary plastic stents. Stretching the hepaticojejunostomy to this diameter guarantees adequate bile flow and long-term resolution of the problem. The stents remained in situ for 3 and 4 months. In three patients, additional stenting was performed for a further 3 months.

In summary, this is the first report to detail the use of small caliber stents during balloon-assisted ERCP. Multistenting, using several plastic stents of smaller diameter, offers a promising treatment for complex hepaticojejunostomy strictures. In addition, failure to provide endoscopic therapy would invariably lead to a percutaneous approach to dilate these strictures.

Endoscopy_UCTN_Code_TTT_1AR_2AZ

Competing interests: None

\section{Paul T. Kröner ${ }^{1,2}$, Marco D’Assunçaoo ${ }^{1,3}$, Klaus Mönkemüller ${ }^{1}$}

Basil I. Hirschowitz Endoscopic Center of Excellence, Birmingham, Alabama, USA

2 Department of Internal Medicine,

Mt. Sinai St. Luke's Roosevelt Hospital

Center, New York, USA

${ }^{3}$ Hospital Sirio-Libanes, Sao Paulo, Brazil 


\section{References}

1 Neumann H, Fry LC, Meyer F et al. Endoscopic retrograde cholangiopancreatography using the single balloon enteroscope technique in patients with Roux-en-Y anastomosis. Digestion 2009; 80: $52-57$

2 Saleem A, Baron TH, Gostout CJ et al. Endoscopic retrograde cholangiopancreatography using a single-balloon enteroscope in patients with altered Roux-en-Y anatomy. Endoscopy 2010; 42: 656-660

3 Skinner M, Popa D, Neumann $H$ et al. ERCP with the overtube-assisted enteroscopy technique: a systematic review. Endoscopy 2014; 46: 560-572

\section{Bibliography}

DOI http://dx.doi.org/

10.1055/s-0034-1391653

Endoscopy 2015; 47: E208-E209

(c) Georg Thieme Verlag KG

Stuttgart · New York

ISSN 0013-726X

\section{Corresponding author}

\section{Klaus Mönkemüller, MD}

Division of Gastroenterology and Hepatology, Basil I. Hirschowitz Endoscopic

Center of Excellence

Endoscopy Unit, JT 664

619 19th Street S

Birmingham, AL 35249

Fax: +39-49-343769

klaus1@uab.edu 